\title{
UFRRJ SEROPÉDICA: SITUAÇÕES DE CONFLITOS E VIOLÊNCIAS
}

Iris de Macedo Rosa ${ }^{1}$

Resumo:

O presente trabalho é fruto da monografia intitulada "Estudo exploratório sobre situações de violências no campus da UFRRJ Seropédica" defendida em 2016 que visou analisar as narrativas e organizações em torno de situações de violências ocorridos no campus da UFRRJ; levando em considerações o aumento de pessoas circulando na cidade de Seropédica e no campus bem como a expansão do sentimento de insegurança a partir da expansão que a universidade passou após o REUNI. Para esta ocasião trago as principais análises e reflexões que a mesma proporcionou. $\mathrm{O}$ trabalho de natureza qualitativa leva em consideração os anos de 2014 a 2016, apontando as situações de violências que ocorreram e ganharam repercussão da mídia, além das formas de mobilização que foram produzidas pelas redes sociais e pelos coletivos para visibilizar e tonar uma questão pública as forma de violências e ameaças com mulheres da UFRRJ. Deste modo esperase analisar como a questão da segurança interna entrou para a agenda da comunidade acadêmica.

Palavras chave: Violências, direitos, mobilizações, segurança, gênero \& juventude.

\section{UFRRJ SEROPÉDICA: SITUATIONS OF CONFLICTS AND VIOLENCES.}

Abstract: The present research is the result of the monograph entitled "Exploratory study on situations of violence in the campus of UFRRJ Seropédica" presented in 2016 that aimed to analyze the narratives and organizations around situations of violence occurred in the UFRRJ campus, taking into consideration the increase of people circulating in the city of Seropédica and in the campus as well as the increase of the insecurity feeling from the expansion that happened in the university after REUNI. Because of Thais facts, I am raising some reflections And Also an analysis provided by it. This qualitative research takes into consideration the years of 2014 to 2016, pointing out the situations of violence that occurred and gained repercussion on the media and the forms of mobilization that were produced by social networks in order to make visible and

\footnotetext{
${ }^{1}$ Graduada em Ciências Sociais pela UFRRJ em 2017. Mestranda do Programa de Pós Graduação em Ciências Sociais da UFRRJ.

CSOnline - Revista Eletrônica de Ciências Sociais, Juiz de Fora, n. 25 (2017), pp. 1-296.
} 
turn into a public question the forms of violence and Threats against UFRRJ women. In this way, we expect to analyze how security has entered in the agenda of the academic community.

Key words: Violence, rights, mobilizations, security, gender and youth.

\section{Introdução}

Este trabalho decorre da monografia intitulada "Estudo exploratório sobre situações de violências no campus da UFRRJ Seropédica" defendida no ano de 2016 por ocasião da graduação no curso de licenciatura plena em Ciências Sociais pela UFRRJ. O trabalho visou analisar as narrativas e organizações em torno de situações de violências ocorridos no campus da UFRRJ; levando em considerações o aumento de pessoas circulando na cidade de Seropédica e no campus bem como a expansão do sentimento de insegurança a partir da expansão que a universidade passou após o REUNI. O trabalho levou em consideração os anos de 2014 a 2016, apontando as situações de violências que ocorreram e ganharam repercussão da mídia e as formas de mobilização que foram produzidas pelas redes sociais para visibilizar e tonar uma questão púbica as forma de violências e ameaças com mulheres da UFRRJ. Ao fim apresentei dados estatísticos sobre percepção de insegurança no campus da UFRRJ coletados com pessoas que acessam o campus e que indicou a necessidade de maior produção de segurança.

Para esta ocasião trago o recorte acerca da construção de mobilizações e ações coletivas pela segurança no campus sede da UFRRJ no município de Seropédica. O objetivo desta pesquisa compreende o mapeamento e identificação dos coletivos e organizações que se articulam para produzir alguma forma de informação que tangem a segurança, reivindicam maior amparo institucional e fornecem suporte às vitimas. A pesquisa caracteriza-se como uma investigação exploratória e de natureza qualitativa. Busca-se elaborar um mapeamento de percepções e relatos de violência no campus, assim como a identificação de processos de administração de conflitos para conhecer qualificadamente os diferentes problemas relativos à segurança no campus de Seropédica da UFRRJ.

Desde modo, este artigo tem como proposta analisar casos e denúncias de violências bem como as formas de mobilizações ocorridas na UFRRJ entre o período de 2014 a 2016. Nesse sentido foi observado os impactos da expansão da UFRRJ principalmente no que tange a área de segurança no campus de Seropédica em diálogo com a conjuntura local dos processos - situações de violência.

CSOnline - Revista Eletrônica de Ciências Sociais, Juiz de Fora, n. 25 (2017), pp. 1-296. 


\section{A Universidade Federal Rural do Rio de Janeiro}

A Universidade pública é um espaço de autonomia política, administrativa, financeira, didática e disciplinar. Essa situação a coloca em um lugar específico, tanto em relação às possíveis formas de intervenção das instituições de segurança pública, quanto às políticas e medidas que ela defina e adote para administrar a segurança dentro de seu patrimônio (contratação de serviços terceirizados, designação de servidores públicos para tais funções etc.). Para esta análise, deve-se também considerar que os problemas cotidianos de insegurança da Baixada Fluminense, mais especificamente do município de Seropédica, se fazem sentir no campus da Universidade Federal Rural do Rio de Janeiro.

A UFRRJ a partir de 2009 passou por uma significativa transformação, após a implementação do Projeto Reestruturação e Expansão das Universidades Federais (sigla REUNI) do Governo Federal. A Universidade que em 2005 contava com 7.000 mil alunos e 22 cursos de graduação, atualmente oferece 57 cursos e cerca de 18 mil alunos de matriculados ${ }^{2}$. Isso significou uma alteração na dinâmica do Campus Universitário e das formas de administração dos espaços sociais, incluindo o alojamento universitário, onde residem oficialmente cerca de 1.500 mil alunos dentro do campus. Nesse sentido, ocorreu um aumento nos conflitos sociais e diferentes formas de violências ocorridas dentro do campus decorrentes do aumento de pessoas circulando e morando nos alojamento universitários, o que vem produzindo certas mobilizações de associações estudantis que reclamam da ausência de projetos institucionais de redução de riscos. Do mesmo modo, o número de estudantes que atualmente moram na cidade de Seropédica aumentou, ocasionado situações de furtos em residências, assaltos e tentativas de estupros veiculadas pela mídia nos anos de 2014 e 2015.

É preciso destacar algumas situações de violências e crimes de maior repercussão e/ou ocorrência destacadas. As tentativas de estupro nos arredores do campus e mesmo com alunas que residem na cidade produziram reações e a organização de coletivos e movimentos. Oficialmente, foram poucas situações ocorridas com alunas da UFRRJ, contudo produziram enorme alarde social e manifestações públicas, vale ressaltar que os dados divulgados pela Divisão de Guarda e Vigilância da UFRRJ não estão em números absolutos, apenas em porcentagem, o que impede o conhecimento do número exato de

\footnotetext{
${ }^{2}$ UFRRJ. A Rural Hoje. <http://portal.ufrrj.br/institucional/a-rural-hoje/>. Acesso em novembro de 2016. CSOnline - Revista Eletrônica de Ciências Sociais, Juiz de Fora, n. 25 (2017), pp. 1-296.
} 
registros. Contudo, é preciso destacar que segundo pesquisa de autoria própria (2016) através de instrumento de pesquisa de opinião realizada com membros da comunidade acadêmica, $79 \%$ dos respondentes relataram que sentem-se inseguros ao frequentar o campos.

\section{Mobilização e ações coletivas em prol da segurança no campus da UFRRJ}

$\mathrm{O}$ pouco amparo institucional no que tange às questões que envolvem insegurança e situações de violências em diferentes campi universitários instigou os estudantes a estarem cada vez mais unidos a fim de encontrarem suporte uns nos outros, para que mobilizados pudessem reivindicar por melhores condições de segurança nas universidades. São os chamados Coletivos, que vão se espalhando pelas IES com o objetivo de denunciar crimes, ataques, impunidades, além de dialogar e cobrar das instâncias superiores das universidades medidas para solucionar os problemas enfrentados diariamente por quem circula nos campi.

O debate acerca da segurança no campus de Seropédica da UFRRJ veio acompanhado do aumento do número de atos violentos que vieram à tona e chegaram ao conhecimento da comunidade. As reações se deram em através de mobilizações e manifestações em prol da segurança; da formação de coletivos; de ferramentas que permitem a comunicação e diálogo entre os frequentadores do campus.

Cotidianamente, a violência remete ao uso da força que alguém ou um grupo exerce sobre uma determinada pessoa ou outro agrupamento. Entretanto, cabe destacar que a violência é um fenômeno variável de acordo com o contexto e com os significados que produz. Ou seja, a violência pode adquirir diversos sentidos: uso da força física contra alguém ou para forçar alguém a realizar alguma ação; coação; constrangimento e há também crimes como roubo com ameaça e homicídio, formas de violência tipificadas como infrações penais. Então, este trabalho entende como violência toda ação compreendida como uma interferência de qualquer ordem física, moral, simbólica, de violação de direitos, de perturbações e sofrimento relativas a alterações que um ou mais indivíduo causam a outro(s), ao infringir as leis estatais ou morais/sociais previamente pactuadas. (PINTO, 2014).

2.1 Casos de violências em Universidades no Brasil que tiveram visibilidade CSOnline - Revista Eletrônica de Ciências Sociais, Juiz de Fora, n. 25 (2017), pp. 1-296. 
Faz-se necessário destacar que a UFRRJ não é um caso isolado, ela está inserida numa conjuntura onde em IES de todo o país, alunos relatam problemas vinculados à segurança no interior dos campi.

Nos últimos anos as denúncias de estupro sofrido por universitárias se espalham por todo o país, sejam elas públicas ou privadas. Em pesquisa encomendada pelo Instituto Natura ao Data Popular ${ }^{3}$ revelou ouviu 1.823 universitários das cinco regiões do Brasil entre 16 e 35 anos. O estudo revelou que $67 \%$ das entrevistadas já sofreram algum tipo de violência - sexual, psicológica, moral ou física - no ambiente universitário e $38 \%$ dos homens admitiram já ter cometido algum tipo de violência contra mulheres também no ambiente universitário.

\footnotetext{
"Os casos frequentes fizeram com que $42 \%$ das alunas sentissem medo da violência nos ambientes universitários e $36 \%$ delas já deixaram de fazer alguma atividade acadêmica por isso. O levantamento ainda mostrou que $49 \%$ das alunas já foram desqualificadas intelectualmente no ambiente universitário por serem mulheres, com piadas ou sátiras de gênero. O levantamento mostrou também que, embora dois terços das alunas sofreram violência, $63 \%$ não reagiram. A maioria delas, por medo de ser exposta (61\%). Das que contaram, um terço sofreu represálias, como ser hostilizada, ficar isolada ou ser exposta na universidade. - É preciso pensar uma solução para esse problema que passe pela responsabilização de todos os componentes da comunidade acadêmica - afirmou Renato." (Presidente do Data Popular, Renato Meirelles. 2015)
}

Trago agora casos de grande repercussão no país e que ajudaram a trazer ao grande público o debate acerca da gestão da segurança nos campi universitários. Em agosto de 2014 uma aluna que não quis se identificar foi atacada no estacionamento da Faculdade de Arquitetura e Urbanismo da USP, a tarde, quando entrava no carro. A aluna conta que recebeu vários bilhetes com ameaças de seu agressor e desde então procurou ajuda do coordenador do seu curso, que prometeu passar nas salas falando sobre o assunto, porém nada foi feito. Após sofrer o ataque a aluna foi à polícia para fazer boletim de ocorrência e exame de corpo de delito. Como a aluna não conseguiu ver o rosto do agressor, foi orientada a procurar a segurança da universidade para procurar nas gravações das câmeras o momento do ataque e assim identificar o agressor. Ao procurar a guarda universitária, foi

\footnotetext{
${ }^{3} \mathrm{ZH}$ Notícias. Quase 70\% das mulheres já sofreram violência em universidades, mostra pesquisa. <http://zh.clicrbs.com.br/rs/noticias/noticia/2015/12/quase-70-das-mulheres-ja-sofreram-violencia-emuniversidades-mostra-pesquisa-4921846.html >Acesso em janeiro de 2015.

CSOnline - Revista Eletrônica de Ciências Sociais, Juiz de Fora, n. 25 (2017), pp. 1-296.
} 
informada que as mais de 100 câmeras espalhadas na universidade não funcionavam há um ano ${ }^{4}$.

Também em São Paulo, uma aluna recorreu ao Ministério Público para denunciar os casos de descriminação, assédio e violência na Faculdade de Medicina da USP (FMUSP). O inquérito do MP/SP cita além de 8 casos de estupro, ainda 2 casos concretos de discriminação contra homossexuais em festas da FMSP - como foi relatado pelo jornal O Estado de São Paulo na época. Um jovem, que não quis de identificar, disse ter sido impedido de entrar em uma ala da festa "Carecas no Bosque" que só aceitava casais heterossexuais.

Em dezembro de 2014 a Comissão de Direitos Humanos da ALESP abriu uma Comissão Parlamentar de Inquérito (CPI) presidida pelo então deputado Adriano Diogo (PT). Durante entrevista para o Jornal do Campus ${ }^{5}$, o ex-deputado afirmou que sofreu pressão da diretoria da FMUSP para que não fossem realizadas as primeiras audiências públicas, envolvendo casos de trotes e abuso sexual na unidade antes mesmo da abertura oficial da CPI. A CPI - SP investigou casos constantes de violações de direitos humanos não só na FMUSP, mas também na Unicamp e PUC Sorocaba, foram ouvidas mais de 200 pessoas. Os relatos vão desde hinos racistas até abusos corporais, psicológicos e sexuais. A matéria conta que:

\begin{abstract}
“Com fim em março de 2015, o relatório final da CPI determinava 39 recomendações, que não foram levadas adiante pela FM, e responsabilizava as universidades, as entidades promotoras de festas e os agressores pelos crimes. $\mathrm{O}$ documento propunha ainda a criação de uma Ouvidoria Estudantil estadual para atender os casos de assédio sexual, moral e profissional; além de dois projetos de lei: um que proíbe o patrocínio de festas estudantis por fabricantes de bebida alcoólica e outra que cria um cadastro universitário único para relatar o envolvimento de estudantes em trotes. Para Adriano Diogo, presidente da CPI, o principal avanço das audiências foi "desnudar barbaridades que acontecem nas melhores universidades do país, e são abafadas". (Fonte: Jornal do Campos, 2015)
\end{abstract}

\footnotetext{
${ }^{4}$ G1. "Nunca saio sozinha", diz aluna que sofreu uma tentativa de estupro na USP. < http://g1.globo.com/educação/notcia/2014/12/nunca-saio-sozinh-diz-a-aluna-que-sofreu-tentativa-deestupro-na-usp.html>. Acesso e janeiro de 2016.

5 Jornal do Campus. Aos abusos sexuais, silêncio.

<http://www.jornaldocampus.usp.br/index.php/2015/11/aos-abusos-sexuais-silencio/> Acesso em janeiro de 2016.

CSOnline - Revista Eletrônica de Ciências Sociais, Juiz de Fora, n. 25 (2017), pp. 1-296.
} 
Na UFPE no Ceará uma estudante foi atacada em um dos pontos de ônibus da Universidade, o caso tomou conhecimento nacional ao ser noticiado no programa da Rede Globo, Profissão Repórter, que foi ao ar no dia 13 de novembro de $2015^{6}$. O programa mostrou o depoimento da aluna que cursava o primeiro período de biomedicina. A aluna de 19 anos foi estuprada em um terreno sem iluminação que pertence à Universidade. No relato da vítima postado por amigas na página do Facebook do Coletivo Feminista L.I.S, a estudante diz:

"Após o ocorrido eu tive algumas consequências: por causa do estrangulamento eu tive derrame ocular, não saio de casa sozinha, tive que voltar para a minha cidade, e o pior de tudo, desisti do meu sonho de me formar na UFPE. Sim, esses acontecimentos destroem sonhos e "tiram" a liberdade de viver." Fonte: Facebook

Apresento agora o debate para a esfera local na Universidade Federal Rural do Rio de Janeiro onde se concentra esta pesquisa.

\subsection{A violência contra a mulher, sua visibilidade e a repercussão na UFRRJ}

As situações interpretadas como violência não são apenas conceituais, mas um fenômeno empírico que depende das representações, sentidos, percepções e construções sócias que são aos fenômenos atribuídos. Para tanto, trago para esta análise Teoria da Representação Social. O conhecimento via representações sociais é um tipo de conhecimento que chegase a ele interrogando a realidade através do que se pensa sobre ela. Exemplificando, ao invés de centrar a análise nos dados brutos da violência, interrogam-se os imaginários construídos sobre a violência. Assim, trabalha-se a noção como um todo e sempre no plural, assumindo as representações sociais enquanto uma teia ou rede de significações onde estas, embora resultado de experiências individuais, são condicionadas e dependentes das inserções sociais dos indivíduos que as produzem (PORTO, 2006). Segundo Durkheim:

[...] sendo representações coletivas são comuns à um grupo social inteiro \{e\} correspondem à maneira como esse ser especial que é a sociedade pensa as coisas de sua experiência própria... mesmo quando essas representações têm o caráter geral, que lhes é mais habitual, elas são obra da sociedade e ricas de sua experiência (Durkheim, 1985, p. $621)$.

${ }^{6}$ G1 Profissão Repórter. Escuridão que afeta a vida da gente. <http://g1.globo.com/profissaoreporter/noticia/2015/11/escuridao-que-afeta-vida-da-gente.html>. Acesso em janeiro de 2016. CSOnline - Revista Eletrônica de Ciências Sociais, Juiz de Fora, n. 25 (2017), pp. 1-296. 
Dessa forma, entendemos nessa pesquisa que as mobilizações que foram produzidas pelos diferentes coletivos e grupos organizados na UFRRJ produziram novos significados e representações sobre o fenômeno - e os sentidos - das diversas formas de violência que já ocorreram no campus. As situações de violência narradas e publicizadas assumiram contornos e significados para além da dinâmica do campus, e alcançaram a comunidade acadêmica e do município. Assim construíram-se mobilizações a partir de experiências vividas que problematizaram as situações de violências, especialmente contra mulheres e ampliaram as representações e significados das situações interpretadas como violências dentro do campus.

Na UFRRJ, as tentativas de estupro, roubos e assaltos nos arredores do campus e mesmo com alunas que residem na cidade gerou a mobilização de setores da comunidade. Numa ordem cronológica das reações da comunidade destaco aqui as de maior relevância.

A página "Abusos Cotidianos - UFRRJ"7 foi criada por uma aluna do curso de psicologia que possui 22 anos, na descrição da página na rede social a criadora conta que a página "surgiu com a necessidade de criação de um ambiente seguro e acolhedor para dar voz as vítim@s de abusos cotidianos dentro da UFRRJ". A página é um lugar de desabafo e acolhimento onde as vítimas escrevem afim de encontrar o apoio que não recebem pela via institucional. As vítimas mandam suas denuncias e relatos através de mensagem para a página, aqueles que as vitimas permitem, são postados com o nome da vítima sendo ocultado, bem como do agressor.

Em entrevista concedida pela criadora da página para a realização do presente trabalho, a criadora da página contou que quando cursava o $2^{\circ}$ período do curso de psicologia da universidade em 2013 sofreu uma tentativa de estupro no Instituto de Ciências Humanas e Sociais (ICHS), ao contar a sua amiga o ocorrido, a amiga revelou também já ter sido vítima de tentativa de estupro dentro da Universidade. Segundo relatado "Foi então que eu percebi que deve ter acontecido com mais meninas. Criei a página pra ser um espaço de denúncia onde as meninas pudessem contar suas histórias. [...] Em sete dias já haviam 7 relatos."

\footnotetext{
${ }^{7}$ https://www.facebook.com/AbusosCotidianosUfrrj/ CSOnline - Revista Eletrônica de Ciências Sociais, Juiz de Fora, n. 25 (2017), pp. 1-296.
} 
As denúncias que chegam à página são em sua maioria referentes a assédio físico/ psicológico e tentativa de estupro. Alunas e também funcionárias relatam já terem sido coagidas por professores que dão nota baixa e ridicularizam vítimas que não sedem às suas investidas; técnicos administrativos oferecem carona e tranca a porta do carro permitindo a saída da vítima apenas após um beijo; há relatos de agressões em festas e no alojamento.

A aluna conta que o ao receber uma denúncia a primeira atitude é checar a veracidade e logo em seguida orienta as vítimas a denunciarem na Delegacia da Mulher em Campo Grande/RJ e na Reitoria. A aluna também apresenta o atendimento psicológico que a universidade disponibiliza. Porém, na maioria das vezes as meninas não querem denunciar por desacreditarem da punição dos seus agressores.

A página, Abusos Cotidianos, cumpre o papel que muitas das vítimas esperam receber da UFRRJ, que é dar suporte e amparo às vítimas de violência que fazem parte da comunidade acadêmica. Entretanto, não acaba aí a responsabilidade da Universidade, esta deve garantir a segurança daqueles que estão no campus e quando este trabalho preventivo não ocorre de modo eficiente, a Universidade deve então punir aqueles que estão violentando moral e fisicamente alunas e funcionárias.

Capítulo IV Do Regime Disciplinar Art. 136 - O regime disciplinar da Universidade obedece à legislação que lhe é pertinente e se fundamenta na necessidade de garantir a disciplina indispensável ao desenvolvimento das atividades universitárias e educativas e no senso de responsabilidade do pessoal 45 docente, técnico-administrativo e discente visando a assegurar, manter e preservar o respeito interpessoal, a dignidade das pessoas e o adequado funcionamento da instituição segundo os princípios da legalidade, da impessoalidade, da moralidade e da publicidade. Parágrafo Único - As sanções disciplinares aplicáveis à comunidade universitária são regulamentadas no Código Disciplinar, aprovado pelo CONSU. (Fonte: UFRRJ, 2012)

Quando questionada se a Reitoria já entrou com contato com a página a fim de estabelecer um diálogo ou parceira, a criadora da página afirmou que, atualmente não há diálogo, a baixo segue a resposta na íntegra.

"Não. A violência na Rural é institucionalizada. Quando sofri a tentativa de estupro, procurei a reitoria e o vice-reitor Callado me disse que sentia muito, mas o que aconteceu comigo havia sido um caso isolado. E ainda completou dizendo que como estudante de psicologia eu provavelmente lidaria melhor com o ocorrido.

CSOnline - Revista Eletrônica de Ciências Sociais, Juiz de Fora, n. 25 (2017), pp. 1-296. 
Todas as vezes que a página entra em questão em reuniões de $\mathrm{CONSU}^{8}$, CONSUNI $^{9}$, Reitoria eu compareço e a resposta é sempre de que os meus dados não são oficiais. A rural me pede pra entregar os relatos à reitoria e eu não posso fazer isso. São as vítimas quem deveriam se sentir a vontade para contar o que aconteceu com elas à Reitoria, não eu.

É dever da Rural manter o mato cortado, a ciclovia iluminada, mas principalmente garantir que as vítimas sejam amparadas e os agressores punidos. Nem sempre o perigo vem de fora da universidade e a Rural simplesmente não dá seguimento às sindicâncias que são abertas, inviabiliza as investigações, arquiva processos.

O meu caso por exemplo... quando fui até a guarda relatar o ataque, contei toda a movimentação que aconteceu. Ainda levei uma bronca da guarda porque não deveria estar andando sozinha no campus num domingo às 18:00. Depois de um tempo fui procurar o registro da minha ocorrência e estava descrita como "agarrão pelo pescoço". A guarda não cria registros que manchem a imagem da Universidade." (Fonte: Entrevista com criadora da página Abusos Cotidianos - UFRRJ.)

Até o dia da realização da entrevista em 4 de abril de 2016, a página Abusos Cotidianos - UFRRJ já havia recebido 615 denúncias de vítimas da UFRRJ, com relatos que datam desde 1970 até a atualidade.

No ano de 2014 foi organizado o Comitê de Auto Defesa das Mulheres da UFRRJ. O Comitê é composto por membros da UFRRJ e se define como um espaço de luta, classista e combativo. Além de organizar reuniões frequentes, atos e manifestações, o Comitê produziu uma petição ${ }^{10}$ de "Repúdio aos Atos de Violência Contra as Mulheres na UFRRJ e Seropédica" online pela plataforma Avaaz, endereçada ao Senado Federal, pedindo intervenção federal na UFFRJ. A petição conta com denúncias e exigências a reitoria. Nas exigências constam:
1) ampliação e manutenção constante da iluminação no campus;
2)transporte interno, frequente e gratuito;
3) melhoria da zeladoria do campus, capina e controle da vegetação;
4) estrutura para pronto atendimento ao registro e denúncia dos atos de violência sexual;

5) política de acolhimento à vítima. (Fonte: Petição Pública Brasil.)

\footnotetext{
${ }^{8}$ Conselho Universitário UFRRJ.

${ }^{9}$ Conselho de Unidade UFRRJ.

${ }^{10}$ Petição Pública. Repúdios aos atos de violência na contra as mulheres na UFRRJ e Seropédica. <http://www.peticaopublica.com.br/pview.aspx?pi=CAD>. Acesso em: novembro de 2015.

CSOnline - Revista Eletrônica de Ciências Sociais, Juiz de Fora, n. 25 (2017), pp. 1-296.
} 
Outra via de denúncia e alerta desenvolvida por uma aluna da UFRRJ foi a página "Minha Rural"11. A aluna Sarah Fernn do curso de administração, criou a página em 2014 com o intuito de ser uma via de comunicação direta com os alunos da universidade. A ideia surgiu da constante queixa dos alunos em relação a má divulgação da Universidade para dar notícias, divulgar eventos, fazer comunicados, entre outros. Sarah decidiu então ela mesma buscar as informações/notícias que até então eram dispersas e centralizar num único lugar que seria a referência para os alunos da UFRRJ. Desde então a página Minha Rural passou a oferecer a comunidade acadêmica o local onde são divulgados eventos, notícias, oportunidade de estágio, festas e principalmente comunicar acontecimentos no interior do campus praticamente em tempo real.

Em entrevista concedida para a realização deste trabalho, Sarah relatou que percebeu a carência de informação acerca do que acontecia no dia a dia da universidade em detrimento da distância entre os institutos. A criadora da página percebeu que se algo de interesse de todos ocorresse no Instituto de Biologia, um aluno que frequenta apenas o Instituto de Zootecnia não tem um meio de ser informado. Segundo a aluna, sua principal preocupação inicial era criar uma ferramenta capaz de alertar para questões relativas a segurança no interior da universidade e nos ambientes frequentados pelos alunos da UFRRJ.

Os alunos encaminham o suas denúncias para a Minha Rural a fim de alertar e divulgar os acontecimentos "ruralinos". Sarah contou que as denúncias relativas a segurança mais frequentes são de roubos, assaltas e arrombamentos.

As situações ocorridas com estudantes da UFRRJ, produziram enorme alarde social e manifestações públicas também de órgãos institucionais. A Associação dos Docentes da Universidade Federal Rural do Rio de Janeiro publicou na edição n ${ }^{\circ} 163$ de junho de 2014 da sua revista uma matéria onde retrata a situação precária da DGV e do campus de Seropédica, bem como a cobertura de manifestações feitas pelos discentes e sua reivindicações. A matéria ainda contou com esclarecimentos da Administração Central através do vice-reitor Callado e do diretor da DGV Canuto onde assumem o compromisso

\footnotetext{
${ }^{11} \mathrm{https}: / /$ www.facebook.com/minharural/ CSOnline - Revista Eletrônica de Ciências Sociais, Juiz de Fora, n. 25 (2017), pp. 1-296.
} 
de investir e melhorias. Eles também falaram sobre as dificuldades em lidar com um contingente pequeno ${ }^{12}$.

Do mesmo modo o número de estudantes que atualmente moram na cidade de Seropédica aumenta nos períodos letivos, ocasionado uma percepção entre os alunos que o número situações de furtos e risco é mais elevado, além disso percebeu-se que assaltos e tentativas de estupros na cidade foram mais recorrentemente veiculadas pela mídia nos anos de 2014 e 2015. Dentre várias, a matéria que mais chocou não só a comunidade universitária e local, mas também toda a região, diz respeito ao caso em outubro de 2014 no qual uma aluna surgiu na ciclovia aos gritos e com a mão ensanguentada ao resistir a uma tentativa de estupro. A matéria veiculada pelo Jornal O Globo e noticiada pelo canal Record, conta que a polícia civil e militar foi acionada e perseguiu o agressor. A reitora Ana Dantas declarou na ocasião que o ataque aconteceu fora do campus e afirmou estar buscando mais recursos do $\mathrm{MEC}^{13}$.

Em junho de 2015 o Departamento Ciências Sociais promoveu o debate "Violência sexual no campus Seropédica: uma questão de agora?" motivado pelo ataque a uma aluna de ciências sociais que cursava o primeiro período de 2015-1. A aluna foi estuprada no bairro Fazenda Caxias que pertence ao município de Seropédica. O debate contou com a participação de especialistas em gênero, representantes da reitoria e de grupos organizados que combatem que denunciam a violência no campus ${ }^{14}$.

Outra situação que merece destaque são as situações de trotes vexatórios e humilhantes que ocorrem no alojamento universitário e em integrações de cursos. ${ }^{15}$ dentro do alojamento universitário e com calouros que ingressam na Universidade. Tais práticas vem sendo combatidas com veemência pela Reitoria. Mas ocorre; ainda dentro dos alojamentos conflitos/ brigas de convivência entre diferentes perfis de alunos que ocasionaram alguns Processo Administrativo Disciplinar, (como por exemplo ameaças

\footnotetext{
${ }^{12}$ Boletim do Sindicato de professores ADUR sobre Violência no Campus e mobilizações conjuntas realizadas - novembro de 2015.

Pagina no Facebook para denúncias de violência contra Mulher e ouras violências no campus da UFRRJ Repúdio aos atos de violência contra as mulheres na UFRRJ e Seropédica. Manifesto do Comitê de Auto Defesa das Mulheres da UFRRJ - dezembro de 2014.

${ }^{13} \mathrm{O}$ Globo. Aluna da UFRRJ sofre tentativa de estupro nos arredores da Universidade, em Seropédica. Disponível em: <oglobo.globo.com/sociedade/educacao/aluna-da-ufrrj-sofre-tentativa-de-estupro-nosarredores-da-universidade-em-seropedica-14114361> Acesso em novembro de 2015. ${ }^{14}$ https://www.facebook.com/events/477399585759651/.

15 Práticas como raspar/ cortar o cabelo dos alunos, tomar água de peixe podre, beber esperma de cavalo, servir bebida aos veteranos, empurrar automóveis ladeira acima.

CSOnline - Revista Eletrônica de Ciências Sociais, Juiz de Fora, n. 25 (2017), pp. 1-296.
} 
aos homossexuais no alojamento). Além disso, situações de roubos e furtos dentro do campus que contabilizaram no ano de 2014, cinquenta oito $\operatorname{casos}^{16}$.

A mais recente mobilização de estudantes em prol de melhores condições de segurança no campus deu-se através do movimento feminista auto organizado "Me avisa quando chegar". O movimento surgiu aproximadamente em abril de 2016 e inicialmente contou com 2.700 "ruralinas" em suas atividades.

O "Me avisa" - assim chamado pelas alunas - surgiu após mais um caso de violência sexual. Uma aluna foi estuprada durante uma festa de integração do curso de biologia. A festa ocorreu no Quiosque da Reitoria - dentro do campus - no final de março de 2016. O caso foi amplamente repercutido em toda Universidade. Diante da pouca efetividade da Reitoria em aplicar medidas que inibam a violência, alunas se reuniram e começaram a organizar o movimento "Me avisa quando chegar UFRRJ". O nome veio do hábito quase que cotidiano das alunas de pedirem umas as outras que deem notícias quando chegarem aos seus destinos por receio de que algo aconteça no caminho.

Desde que o grupo se constituiu foram organizadas reuniões, assembleias e debates além de realizar diversos atos no campus denunciando a violência e a omissão da Reitoria da Universidade.

A primeira ação foi improvisada, organizada através do grupo criado no Whatsapp intitulado "Feministas da UFRRJ" e do grupo no Facebook "Me avisa quando chegar". A ação se deu no P1 (Pavilhão Principal), a vestimenta escolhida para as ações foi a blusa preta e batom vermelho, seria a representatividade de futuros dias de luto e resistência, pelo descaso e abandono das mulheres dentro do campus. Antes do segundo passo, o movimento já alcançava visibilidade em outras universidades que, através de notas emitidas, compreendiam e apoiavam luta das "ruralinas".

${ }^{16}$ Dados fornecidos pela Divisão de Guarda e Vigilância da UFRRJ.

CSOnline - Revista Eletrônica de Ciências Sociais, Juiz de Fora, n. 25 (2017), pp. 1-296. 


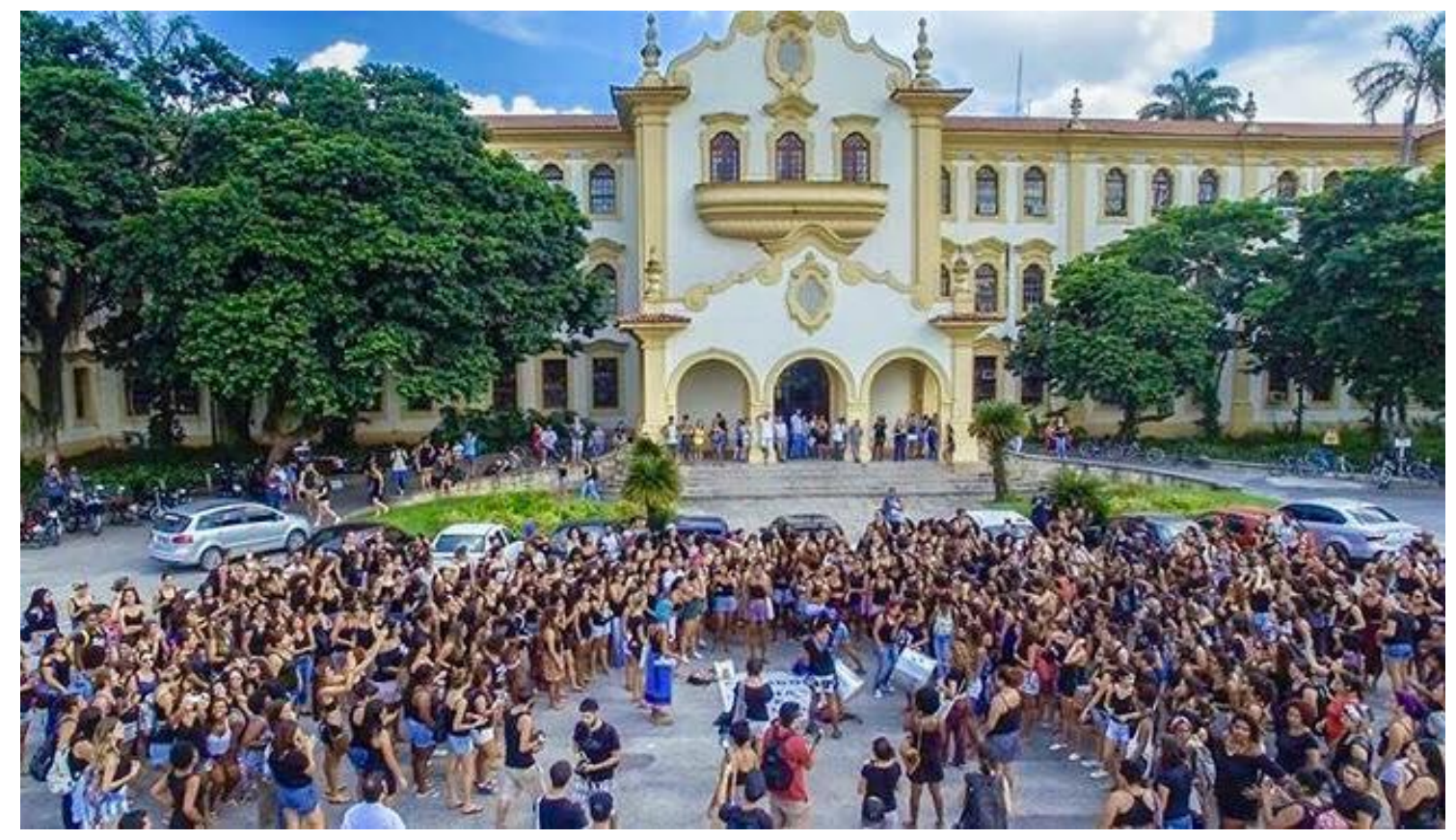

Fonte: Me Avisa Quando Chegar / 2016.

Dentre as ações de maior representatividade está o abraço simbólico dado pelas mulheres no P1. Durante o ato em forma de jogral era repetido que naquele dia as "ruralinas" abraçavam a Universidade e esperavam ser abraçadas e principalmente amparadas de volta por ela.

\begin{abstract}
"A gente ta aqui hoje pra mais uma ação do movimento auto organizado da Rural. Nós agora vamos dar um abraço no p1. Por que nós vamos abraçar o p1? Hoje a nossa ação de abraçar o p1 é pra dizer que nós abraçamos a Universidade e queremos se abraçadas por ela. É pra dialogar com essa galera que reclamou das pichações. A Rural é nossa e a gente precisa se sentir segura aqui. A gente vai abraçar o p1 hoje porque nós somos muitas, a gente abraça o mundo se a gente quiser. A gente vai abraçar o $\mathrm{p} 1$ hoje porque a gente quer que Universidade Rural e toda a sociedade abrace a nossa causa. Porque a gente não quer mais ser estuprada, ser violentada, ser assediada dentro e fora da Universidade. A gente vai abraçar o p1 hoje pra essa Universidade entender que aqui tem mulher de luta! A gente quer ser respeitada! As mulheres da Rural são de luta!" (Autora: Larissa Cabral, aluna do curso de engenharia agrônoma, integrante do Coletivo de Mulheres e da Comissão de Comunicação do Me Avisa Quando Chegar UFRRJ.)
\end{abstract}

O apoio ao movimento veio de IES não só do RJ - UFRJ, UNIRIO, UFF - mas também de fora do estado. Também houveram manifestações em apoio dos cantores Gabriel O Pensador e Lenine, e divulgações do movimento em jornais online as mídias impressas como o Jornal de Seropédica, e canais de televisão como Globo e Record. 
Diante de tanta luta e organização, o movimento conquistou um dia de "Luto em Luta", em que todas as atividades de todos os cursos da universidade foram suspensas em prol de mesas de debates e palestras com temas feministas, e também, um espaço para construção masculina sobre a luta feminista e sua importância.

Até o mês de julho de 2016, o movimento "Me avisa quando chegar UFRRJ" realizou mais de três diálogos com a reitoria da Universidade e 2 grandes assembleias estudantis e ouvidoria na Alerj - Assembleia legislativa do estado do Rio de Janeiro ${ }^{17}$. Todas essas ações foram em busca de melhorias estruturais e respostas acerca dos casos de abusos registrados; bem como um posicionamento acerca das medidas administrativas que deveriam ser tomadas contra os agressores e em apoio às vítimas.

Pode-se concluir que a rápida expansão da UFFRJ após o REUNI expôs as fragilidades da Universidade que se fazem sentir na área da segurança. Nos últimos anos, o debate entrou na agenda da comunidade acadêmica e grande visibilidade na grande mídia. A partir do quadro aqui apresentado, é possível afirmar que, a Universidade Federal Rural do Rio de Janeiro possui um histórico recente de luta e mobilização da comunidade acadêmica. Tais setores denunciam o que seria um quadro negligência institucional com condução dos casos de violência no campus, ausência de punição para agressores e pouca políticas de prevenção. Deste modo, docentes, discente e técnicos administrativos se mobilizaram para reivindicar melhorias na área de segurança em diversas ocasiões com pautas claras e objetivas que visam a ação preventiva bem como ações efetivas que assegurem a segurança daqueles que frequentam a Instituição diariamente ${ }^{18}$.

\section{Conclusão}

As violências ocorridas no campus da UFRRJ trouxeram à tona uma face da Universidade que foi historicamente silenciada. As denúncias ganharam repercussão e visibilidade através da mobilização dos setores que compõem a comunidade acadêmica em decorrência do que estes retratam como omissão da administração superior. A sensação

\footnotetext{
${ }^{17}$ Em maio de 2016 ocorreu uma audiência pública com a Comissão de Defesa dos Direitos da Mulher da ALERJ onde as alunas denunciaram os casos de violências no interior do campus. A deputada Enfermeira Rejane (PCdoB/RJ), Presidente do Grupo, disse que o grupo vai estudar medidas a serem propostas para melhorar a segurança da comunidade universitária do estado. Fonte: http://www.alerj.rj.gov.br/Visualizar/Noticia/38464

18 Vale ressaltar que os casos de violência no município de Seropédica que envolvem membros da comunidade acadêmica são vinculados ao nome da Universidade e portanto corroboram com o sentimento de insegurança.

CSOnline - Revista Eletrônica de Ciências Sociais, Juiz de Fora, n. 25 (2017), pp. 1-296.
} 
de insegurança constante ao circular pelas ruas do campus afeta diretamente o cotidiano universitário bem como o êxito do propósito educador e emancipador da Universidade. As reivindicações em prol de melhores condições de infraestrutura, segurança e maior rigor com os casos que geram processo administrativo revelam o caráter afirmativo do movimento que busca acima de tudo a valorização da Universidade e daqueles que não apenas são frequentadores, mas tem também possuem um vínculo com a mesma.

Bibliografia:

ROSA, Iris de Macedo. Estudo exploratório sobre situações de violências na UFRRJ Seropédica. Seropédica, 2016.

PINTO, Nalayne Mendonça. A violência e seus múltiplos sentidos. In: Conflitos e sociedade. Aula 6. Rio de Janeiro: Cederj. Cecierj, 2014.

PORTO, Maria. Stella. Grossi. Crenças, valores e representações sociais da violência. Sociologias. Porto Alegre, ano 8, n. 16, jul./dez. 2006, p. 250-273.

UNIVERSIDADE FEDERAL RURAL DO RIO DE JANEIRO. Estatuto e Regimento. Seropédica, 2012.

Sites consultados:

G1. Profissão Repórter. Escuridão que afeta a vida da gente. <http://g1.globo.com/profissao-reporter/noticia/2015/11/escuridao-que-afeta-vida-dagente.html>. Acesso em janeiro de 2016.

G1. "Nunca ando sozinha" diz aluna que sofreu tentativa de estupro na USP. $<$ http://g1.globo.com/educacao/noticia/2014/12/nunca-ando-sozinha-diz-aluna-quesofreu-tentativa-de-estupro-na-usp.html>. Acesso em janeiro de 2016.

JORNAL DO CAMPUS. Aos abusos sexuais, silêncio. <http://www.jornaldocampus.usp.br/index.php/2015/11/aos-abusos-sexuais-silencio/> Acesso em janeiro de 2016. 
O GLOBO. Aluna da UFRRJ sofre tentativa de estupro nos arredores da Universidade, em Seropédica. Disponível em: <oglobo.globo.com/sociedade/educacao/aluna-da-ufrrjsofre-tentativa-de-estupro-nos-arredores-da-universidade-em-seropedica-14114361> Acesso em novembro de 2015.

PETIÇÃO PÚBLICA. Repúdios aos atos de violência na contra as mulheres na UFRRJ e Seropédica. <http://www.peticaopublica.com.br/pview.aspx?pi=CAD>. Acesso em: novembro de 2015.

ZH NOTÍCIAS. Quase 70\% das mulheres já sofreram violência em universidades, mostra pesquisa. <http://zh.clicrbs.com.br/rs/noticias/noticia/2015/12/quase-70-das-mulheresja-sofreram-violencia-em-universidades-mostra-pesquisa-4921846.html >Acesso em janeiro de 2015. 